Article

\title{
Photorespiration Enhances Acidification of the Thylakoid Lumen, Reduces the Plastoquinone Pool, and Contributes to the Oxidation of P700 at a Lower Partial Pressure of $\mathrm{CO}_{2}$ in Wheat Leaves
}

\author{
Shinya Wada ${ }^{1,2}\left(\mathbb{D}\right.$, Yuji Suzuki ${ }^{2,3}(\mathbb{C})$ and Chikahiro Miyake ${ }^{1,2, *(1)}$ \\ 1 Department of Biological and Environmental Science, Faculty of Agriculture, Graduate School of \\ Agricultural Science, Kobe University, 1-1 Rokkodai, Nada, Kobe 657-8501, Japan; \\ swada@penguin.kobe-u.ac.jp \\ 2 Core Research for Environmental Science and Technology, Japan Science and Technology Agency, \\ K's Goban-Cyo, 7 Goban-Cyo, Chiyoda-Ku, Tokyo 102-0076, Japan; ysuzuki@iwate-u.ac.jp \\ 3 Faculty of Agriculture, Iwate University, 3-18-8 Ueda, Morioka, Iwate 020-8550, Japan \\ * Correspondence: cmiyake@hawk.kobe-u.ac.jp
}

Received: 9 December 2019; Accepted: 27 February 2020; Published: 3 March 2020

\begin{abstract}
The oxidation of P700 in photosystem I (PSI) is a robust mechanism that suppresses the production of reactive oxygen species. We researched the contribution of photorespiration to the oxidation of P700 in wheat leaves. We analyzed the effects of changes in partial pressures of $\mathrm{CO}_{2}$ and $\mathrm{O}_{2}$ on photosynthetic parameters. The electron flux in photosynthetic linear electron flow (LEF) exhibited a positive linear relationship with an origin of zero against the dissipation rate $\left(\mathrm{vH}^{+}\right)$of electrochromic shift (ECS; $\Delta \mathrm{pH}$ across thylakoid membrane), indicating that cyclic electron flow around PSI did not contribute to $\mathrm{H}^{+}$usage in photosynthesis/photorespiration. The $\mathrm{vH}^{+}$ showed a positive linear relationship with an origin of zero against the $\mathrm{H}^{+}$consumption rates in photosynthesis/photorespiration $\left(\mathrm{JgH}^{+}\right)$. These two linear relationships show that the electron flow in LEF is very efficiently coupled with $\mathrm{H}^{+}$usage in photosynthesis/photorespiration. Lowering the intercellular partial pressure of $\mathrm{CO}_{2}$ enhanced the oxidation of P700 with the suppression of LEF. Under photorespiratory conditions, the oxidation of P700 and the reduction of the plastoquinone pool were stimulated with a decrease in $\mathrm{JgH}^{+}$, compared to non-photorespiratory conditions. These results indicate that the reduction-induced suppression of electron flow (RISE) suppresses the reduction of oxidized P700 in PSI under photorespiratory conditions. Furthermore, under photorespiratory conditions, ECS was larger and $\mathrm{H}^{+}$conductance was lower against $\mathrm{JgH}^{+}$than those under non-photorespiratory conditions. These results indicate that photorespiration enhances RISE and $\Delta \mathrm{pH}$ formation by lowering $\mathrm{H}^{+}$conductance, both of which contribute to keeping P700 in a highly oxidized state.
\end{abstract}

Keywords: photorespiration; photosynthesis; photosystem I; P700 oxidation; reactive oxygen species; reduction-induced suppression of electron flow (RISE)

\section{Introduction}

Plants, both wild and cultivated, face the threat of oxidative damage from reactive oxygen species (ROS) when they are exposed to environments in which photosynthesis is suppressed [1]. For example, low temperatures, high temperatures, and dryness promote stomata closure, which reduces photosynthesis abilities [2]. In these circumstances, superoxide radicals $\left(\mathrm{O}_{2}{ }^{-}\right)$can be generated through the photoreduction of $\mathrm{O}_{2}{ }^{-}$in photosystem I (PSI), and $\mathrm{H}_{2} \mathrm{O}_{2}$ is generated by the 
disproportionation of $\mathrm{O}_{2}{ }^{-}$[2]. The photoreduction of $\mathrm{O}_{2}$ in PSI is regarded as the main ROS-generating process in photosynthetic organisms exposed to environmental stresses [2]. These ROS increase the risk of oxidative damage.

In angiosperms, ROS generation in PSI has been shown to cause oxidative damage [1,3]. To imitate situations in which electrons accumulate on the PSI acceptor side-situations of environmental stress that lowers photosynthesis efficiency and $\mathrm{NADP}^{+}$regeneration efficiency-the leaves of sunflower plants were illuminated intermittently with saturating lights in darkness (repetitive short-pulse (rSP) illumination treatment). This rSP illumination treatment promoted PSI oxidative damage over time. On the other hand, almost no oxidative damage occurred in photosystem II (PSII) [1,3,4]. Under anoxic conditions, the PSI oxidative damage was suppressed [3]. The rSP illumination treatment promoted ROS generation within PSI, which was thought to be the cause of the oxidative damage. Additionally, this PSI damage also lowered the photosynthesis rate [3,5].

The reaction center chlorophyll P700 in PSI drives the photo-oxidation/reduction cycle. Ground state P700 absorbs light and transitions into its excited state $\left(\mathrm{P} 700^{*}\right)$. Then, oxidized P700 $\left(\mathrm{P} 700^{+}\right)$ is generated when P700* donates electrons to the electron acceptors in the PSI complex (Ao, $\mathrm{A}_{1}, \mathrm{Fx}$, and $\mathrm{F}_{\mathrm{A}} / \mathrm{F}_{\mathrm{B}}$ ) [6]. When leaves are irradiated with a pulse light, $\mathrm{P} 70^{+}$is generated rapidly. However, during the pulse, $\mathrm{P} 700^{+}$decreases and $\mathrm{P} 00^{*}$ accumulates $[1,4,7]$. P700* accumulation promotes electron transfer from $\mathrm{A}_{0}, \mathrm{~A}_{1}, \mathrm{~F}_{\mathrm{X}}$, and/or $\mathrm{F}_{\mathrm{A}} / \mathrm{F}_{\mathrm{B}}$ to $\mathrm{O}_{2}$ to produce $\mathrm{O}_{2}{ }^{-}$. This is the mechanism of $\mathrm{ROS}$ generation in PSI by rSP illumination, as well as a molecular mechanism of PSI oxidative damage.

The accumulation of photoexcited P700* implies that the rate-determining step of the P700 photo-oxidation/reduction cycle is the electron transfer reaction from $\mathrm{P} 700^{*}$ to the electron acceptors on the PSI acceptor side. This has been motivating us to clarify the reason why $\mathrm{O}_{2}$-evolving photosynthesis organisms can safely perform photosynthesis under field conditions $[1,3,4]$. If P700* does not accumulate under pulse light illumination, ROS generation should be suppressed. Therefore, to keep P700* from accumulating, the reduction of $\mathrm{P} \mathrm{O0}^{+}$in the P700 photo-oxidation/reduction cycle should be the rate-determining step of the cycle.

In this study, we conducted rSP illumination treatment under steady-state actinic light (AL) conditions [3]. As the intensity of AL increased, the PSI oxidative damage caused by the rSP illumination treatment was lowered. Furthermore, it was found that an increase in AL intensity increased the proportion of $\mathrm{P} 00^{+}$in the photo-oxidation reduction cycle of P700 in PSI [3]. We revealed a negative relationship between PSI oxidative damage and $\mathrm{P} 700^{+}$accumulation under AL conditions [3]. These results show that $\mathrm{P} \mathrm{CO}^{+}$accumulation lowers the proportion of $\mathrm{P} 700^{*}$, which causes the generation of ROS by pulse illumination.

We clarified that $\mathrm{O}_{2}$-evolving photosynthesis organisms suppress $\mathrm{ROS}$ generation in PSI through P700 oxidation [1,3,4,7-12]. Shimakawa et al. [4], in particular, revealed that a cyanobacterial strain that does not maintain a high level of $\mathrm{P} 700^{+}$suffers from rapid PSI oxidative damage under AL illumination. Nearly 30 years ago, it was reported that under conditions with strong light or a low partial pressure of $\mathrm{CO}_{2}\left(\mathrm{pCO}_{2}\right)$, i.e., conditions with a reduced photosynthetic efficiency, plants display the oxidation of P700 in PSI [13-19]. We suggest that P700 oxidation is a robust physiological response for suppressing ROS generation.

Photorespiration is thought to contribute to P700 oxidation [1,20]. For the PSI reaction center chlorophyll P700 to be kept in a higher oxidized state, the regeneration rate of the ground state of P700 in the photo-oxidation/reduction cycle must be limited by the $\mathrm{P} \mathrm{O0}^{+}$reduction rate. In this study, we attempted to explain the molecular mechanism by which photorespiration facilitates the oxidation of P700. 


\section{Materials and Methods}

\subsection{Plant Materials and Growth Conditions}

The winter wheat cultivar "Norin 61" was used in this study. Seeds were incubated on wet cotton at $4{ }^{\circ} \mathrm{C}$ for 3 days to promote synchronized germination. The moistened seeds were grown in a mixture of soil (Metro-Mix 350; Sun Gro Horticulture, Bellevue, WA, USA) and vermiculite (Konan, Osaka, Japan) in pots $(7.5 \mathrm{~cm}$ length $\times 7.5 \mathrm{~cm}$ width $\times 6 \mathrm{~cm}$ depth). The ratio of soil to vermiculite was 1:1. The plants were grown under standard air-equilibrated conditions in an environmentally controlled chamber set at $25{ }^{\circ} \mathrm{C}$ day $/ 20^{\circ} \mathrm{C}$ night, with a $16 \mathrm{~h}$ light/10 h dark photoperiod and $700-800 \mu \mathrm{mol}$ photon $\mathrm{m}^{-2} \mathrm{~s}^{-1}$ light intensity. They were watered every other day with $0.1 \%$ Hyponex solution (N:P:K = 5:10:5; Hyponex, Osaka, Japan). The plants were grown for at least 6 weeks, and fully expanded, mature leaves were harvested for further analysis.

\subsection{Gas Exchange, Chlorophyll Fluorescence, $P 700^{+}$, Electrochromic Shift, and Spectroscopic Analyses}

Exchanges of $\mathrm{CO}_{2}$ and $\mathrm{H}_{2} \mathrm{O}$ were measured using the GFS-3000 system equipped with a 3010-DUAL gas exchange chamber (Walz, Effeltrich, Germany), in which ambient air was saturated with water vapor at $14.0 \pm 0.1{ }^{\circ} \mathrm{C}$ and the leaf temperature was maintained at $25 \pm 2{ }^{\circ} \mathrm{C}$. The photosynthesis rate $(\mathrm{A})$ and dark respiration rate $(\mathrm{Rd})$ were measured. The photosynthesis rate as a function of the intercellular partial pressure of $\mathrm{CO}_{2}(\mathrm{Ci})$ was determined. Three plants were used for each experiment. Gas exchange parameters were calculated by the software of the GFS-3000 system, which follows the method of von Caemmerer and Farquhar [21].

The chlorophyll fluorescence and $\mathrm{P}^{2} 00^{+}$in PSI were measured with a DUAL-PAM system (Walz), simultaneously with the gas exchange analysis of GFS-3000 (Walz). The chlorophyll fluorescence parameters were calculated as follows [22]: $F_{0}$, minimum fluorescence from a dark-adapted leaf; $F_{0}{ }^{\prime}$, minimum fluorescence from a light-adapted leaf; $\mathrm{F}_{\mathrm{m}}$, maximum fluorescence from a dark-adapted leaf; $\mathrm{F}_{\mathrm{m}}{ }^{\prime}$, maximum fluorescence from a light-adapted leaf; Fs, fluorescence emission from a light-adapted leaf; effective quantum yield of PSII, $\mathrm{Y}(\mathrm{II})=\left(\mathrm{F}_{\mathrm{m}}{ }^{\prime}-\mathrm{Fs}\right) / \mathrm{F}_{\mathrm{m}}{ }^{\prime}$; non-photochemical quenching, non-photochemical quenching $(\mathrm{NPQ})=\left(\mathrm{F}_{\mathrm{m}}-\mathrm{F}_{\mathrm{m}}{ }^{\prime}\right) / \mathrm{F}_{\mathrm{m}}{ }^{\prime}$; and $\mathrm{Q}_{\mathrm{A}}$ oxidized state $(\mathrm{qL})=\left(\mathrm{F}_{\mathrm{m}}{ }^{\prime}-\mathrm{Fs}\right) /\left(\mathrm{F}_{\mathrm{m}}{ }^{\prime}-\right.$ $\left.\mathrm{F}_{\mathrm{o}}{ }^{\prime}\right) \times\left(\mathrm{F}_{\mathrm{o}}{ }^{\prime} / \mathrm{Fs}\right)$. To obtain $\mathrm{F}_{\mathrm{m}}$ and $\mathrm{F}_{\mathrm{m}}{ }^{\prime}$, a saturating pulse light $\left(630 \mathrm{~nm}, 8000 \mu \mathrm{mol}\right.$ photons $\mathrm{m}^{-2} \mathrm{~s}^{-1}$, $300 \mathrm{~ms})$ was applied. Red actinic light $\left(630 \mathrm{~nm}, 500 \mu \mathrm{mol}\right.$ photons $\left.\mathrm{m}^{-2} \mathrm{~s}^{-1}\right)$ was supplied using a chip-on-board LED array. The oxidation-reduction state of P700 in PSI was determined according to the methods of Klughammer and Schreiber [23], as follows: $\mathrm{P}_{\mathrm{m}}$, total amount of photo-oxidizable P700; $\mathrm{P}_{\mathrm{m}}{ }^{\prime}$, maximum amount of $\mathrm{P} 700$ photo-oxidized by the saturating pulse light under actinic light; $\mathrm{P}$, amount of photo-oxidized P700 at a steady state under actinic light; the effective quantum yield of PSI, $\mathrm{Y}(\mathrm{I})=\left(\mathrm{Pm}^{\prime}-\mathrm{P}\right) / \mathrm{Pm}$; the quantum yield of non-photochemical energy dissipation of oxidized $\mathrm{P} 700\left(\mathrm{P}_{000}{ }^{+}\right), \mathrm{Y}(\mathrm{ND})=\mathrm{P} / \mathrm{P}_{\mathrm{m}}$; and the quantum yield of non-photochemical energy dissipation of photo-excited P700 (P700*), $\mathrm{Y}(\mathrm{NA})=\left(\mathrm{P}_{\mathrm{m}}-\mathrm{P}_{\mathrm{m}}{ }^{\prime}\right) / \mathrm{P}_{\mathrm{m}}$. The summation of these quantum yields is 1 ( $\mathrm{Y}(\mathrm{I})$ $+\mathrm{Y}(\mathrm{ND})+\mathrm{Y}(\mathrm{NA})=1)$

We set the intensity of actinic light at $500 \mu \mathrm{mol}$ photons $\mathrm{m}^{-2} \mathrm{~s}^{-1}$, so that we could detect $\mathrm{Y}$ (II) and $\mathrm{Y}(\mathrm{I})$ signals at a lower Ci. Generally, P700 is oxidized under high light and/or low $\mathrm{CO}_{2}$ conditions. At extremely high light (ex. $>1500 \mu \mathrm{mol}$ photons $\mathrm{m}^{-2} \mathrm{~s}^{-1}$ ), Y(II) and Y(I) are too small to allow a precise estimation of them.

For P700 in PSI to be oxidized, the reduction rate of $\mathrm{P} 700^{+}$must be the rate-determining step in the P700 photo-oxidation/reduction cycle. $\mathrm{H}^{+}$accumulation in the lumen of thylakoid membranes, $\Delta \mathrm{pH}$ formation, suppresses the plastoquinol $\left(\mathrm{PQH}_{2}\right)$ oxidation of the cytochrome $(\mathrm{Cyt}) b_{6} / f$ complex, which is called photosynthesis control, to oxidize P700 [24]. To evaluate the contribution of photorespiration to the oxidation of P700 in PSI, the electrochromic shift (ECS) signal was measured. The ECS signal reflects both the $\Delta \mathrm{pH}$ and $\Delta \psi$ across the thylakoid membranes [25,26]. The ECS signal was measured simultaneously with the above gas exchange analysis using the DUAL-PAM system (Walz), equipped with a P515 analysis module [27]. The P515 analysis module monitored the formation of the ECS 
signal due to the carotenoid spectrum shift in response to the membrane potential produced by $\triangle \mathrm{pH}$ and [25]. The magnitude of the ECS signal was evaluated by dark-interval relaxation kinetics (DIRK) analysis $[25,26]$. At the steady state of photosynthesis, actinic light (AL) illumination was transiently turned off for $400 \mathrm{~ms}$. On the turning-off of AL illumination, the ECS signal rapidly decayed. The magnitude of the full decay of the ECS signal reflects the summation of both $\Delta \mathrm{pH}$ and $\Delta \psi$. The decay rate of the ECS signal after the turning-off of AL illumination reflects the activity of ATP synthase in thylakoid membranes $[25,26]$. The half time of the ECS decay reflects the proton conductance $\left(\mathrm{gH}^{+}\right)$, which in turn reflects the apparent rate constant of ATP synthesis catalyzed by ATP synthase and depends on the concentrations of ADP and inorganic phosphate and the catalytic constant of ATP synthase [25,26].

The magnitude of the ECS signal was normalized, as follows [27]. A single turnover flash (10s) was used to illuminate the leaf under far-red light. The ECS signal was induced by the single turnover of PSII, which corresponds to the membrane potential induced by single charge separation. The average value of a single turnover (ST) flash-induced ECS signal $\left(\right.$ ECS $\left._{\mathrm{ST}}\right)$ was $3.73 \pm 0.04 \times 10^{-3} \Delta \mathrm{I} / \mathrm{Io}(n=3)$. Then, the measured ECS signal was divided by ECS $_{\mathrm{ST}}$, and was used as the normalized ECS signal $\left(\mathrm{ECS}_{\mathrm{N}}\right)$ [25] (Equation (1)).

$$
\mathrm{ECS}_{\mathrm{N}}=\mathrm{ECS} / \mathrm{ECS}_{\mathrm{ST}}
$$

The contribution of both $\Delta \mathrm{pH}$ and $\Delta \psi$ to the total ECS signal was separately evaluated after the turning-off of AL illumination over longer periods of darkness [26]. Under all experimental conditions in this study, the contribution of $\Delta \psi$ to $\mathrm{ECS}_{\mathrm{N}}$ was less than $10 \%$ (Figure S1). Therefore, $\mathrm{ECS}_{\mathrm{N}}$ is regarded as mainly representing $\Delta \mathrm{pH}$.

The $\mathrm{H}^{+}$consumption flux $\mathrm{vH}^{+}\left(\mu \mathrm{mol} \mathrm{H} \mathrm{H}^{+} \mathrm{m}^{-2} \mathrm{~s}^{-1}\right)$ is proportional to both $\mathrm{ECS}_{\mathrm{N}}$ and $\mathrm{gH}^{+}$. Namely (Equation (2)),

$$
\mathrm{vH}^{+}=\mathrm{m} \times \mathrm{gH}^{+} \times \mathrm{ECS}_{\mathrm{N}},
$$

where $\mathrm{m}$ is a coefficient that has the dimension of " $\mathrm{mol} \mathrm{H}^{+} \mathrm{m}^{-2}$ ". In this study, we assumed that $\mathrm{m}$ was constant.

\subsection{Ribulose 1,5-Bisphosphate (RuBP) Carboxylation Rate and RuBP Oxygenation Rate in Wheat Leaves}

The RuBP carboxylation rate (vc) and RuBP oxygenation rate (vo) during photosynthesis and photorespiration in wheat leaves were measured by simultaneous chlorophyll fluorescence and $\mathrm{CO}_{2}$ exchange analyses [28,29]. The values for vc and vo were obtained from the following equations (Equations (3) and (4)):

$$
\begin{gathered}
\mathrm{vc}=(1 / 6) \times[\mathrm{Jf} / 2+4 \times(\mathrm{A}+\mathrm{Rd})], \\
\mathrm{vo}=(1 / 6) \times[\mathrm{Jf}-4 \times(\mathrm{A}+\mathrm{Rd})],
\end{gathered}
$$

where Jf is the electron flux in the photosynthetic linear electron flow (LEF) and is equal to $\alpha \times \mathrm{Y}$ (II) $\times$ PFD [30]. The photosynthesis rate (A) and dark respiration rate (Rd) were measured as described above. The photon energy absorbed by the leaves is distributed to both PSII and PSI. The coefficient $\alpha$ is the distribution ratio of the photon energy to PSII in the thylakoid membrane. The value of $\alpha$ for wheat leaves, which was $0.42 \pm 0.02(n=4)$ in this study, was determined following the method of Miyake and Yokota [31]. The term PFD stands for the photon flux density, which is the intensity of light illuminated on the leaves.

\section{4. $\mathrm{H}^{+}$Consumption Rate Estimated from the Stoichiometries of Photosynthesis and Photorespiration}

The $\mathrm{H}^{+}$consumption rate $\left(\mathrm{JgH}^{+}\right)$was estimated from the ATP consumption rate (vATP) during photosynthesis and photorespiration [32]. In $\mathrm{C} 3$ photosynthesis, the ratio of $\mathrm{JgH}^{+}$to vATP is 4.67, because ATP synthase uses $4.67 \mathrm{H}^{+}$ions for the synthesis of one molecule of ATP [33]. The ratio of vATP to the NADPH consumption rate (vNADPH) is $[3+3.5(\mathrm{vo} / \mathrm{vc})] /[(2+2(\mathrm{vo} / \mathrm{vc})]$. Considering 
$\mathrm{JgH}^{+} / \mathrm{vNADPH}=4.67 \times[3+3.5(\mathrm{vo} / \mathrm{vc})] /[(2+2(\mathrm{vo} / \mathrm{vc})]$ and the electrons in photosynthetic linear electron flow for the production of $\mathrm{NADPH}, \mathrm{JgH}^{+}$could be expressed as follows [21] (Equation (5)):

$$
\mathrm{JgH}^{+}=9.34 \times(\mathrm{vc}+\mathrm{vo}) \times[3+3.5(\mathrm{vo} / \mathrm{vc})] /[2+2(\mathrm{vo} / \mathrm{v} \mathrm{c})] .
$$

The values of both vc and vo were estimated as described above.

\section{Results}

\subsection{Characteristics of PSII and PSI Parameters in Response to Changes in the Partial Pressure of $\mathrm{CO}_{2}$}

To examine the effect of photorespiration on the photochemical parameters in PSII and PSI, we modulated the photorespiration rate by manipulating the partial pressure of $\mathrm{CO}_{2}$ $\left(\mathrm{pCO}_{2}\right)$. Photorespiration activity is expected to increase when lowering $\mathrm{pCO}_{2}$ under atmospheric conditions [34-36], and lowering the atmospheric partial pressure of $\mathrm{O}_{2}\left(\mathrm{pO}_{2}\right)(21 \mathrm{kPa})$ to $2 \mathrm{kPa}$ achieves negligible photorespiration activity [34-36]. We set $\mathrm{pO}_{2}$ to $21 \mathrm{kPa}, \mathrm{pCO}_{2}$ to $40 \mathrm{~Pa}$, and the light intensity to $500 \mu \mathrm{mol}$ photons $\mathrm{m}^{-2} \mathrm{~s}^{-1}$. After the photosynthesis rate reached a steady-state level, we increased $\mathrm{pCO}_{2}$ to $100 \mathrm{~Pa}$. Next, we lowered $\mathrm{pCO}_{2}$ to $5 \mathrm{~Pa}$ from $100 \mathrm{~Pa}$, and under all $\mathrm{pCO}_{2}$, we assessed the photosynthesis rate, along with the PSII and PSI parameters (Figures 1 and 2). These assessments were conducted under two $\mathrm{pO}_{2}$ conditions ( $21 \mathrm{kPa}$, normoxic condition; $2 \mathrm{kPa}$, hypoxic conditions).
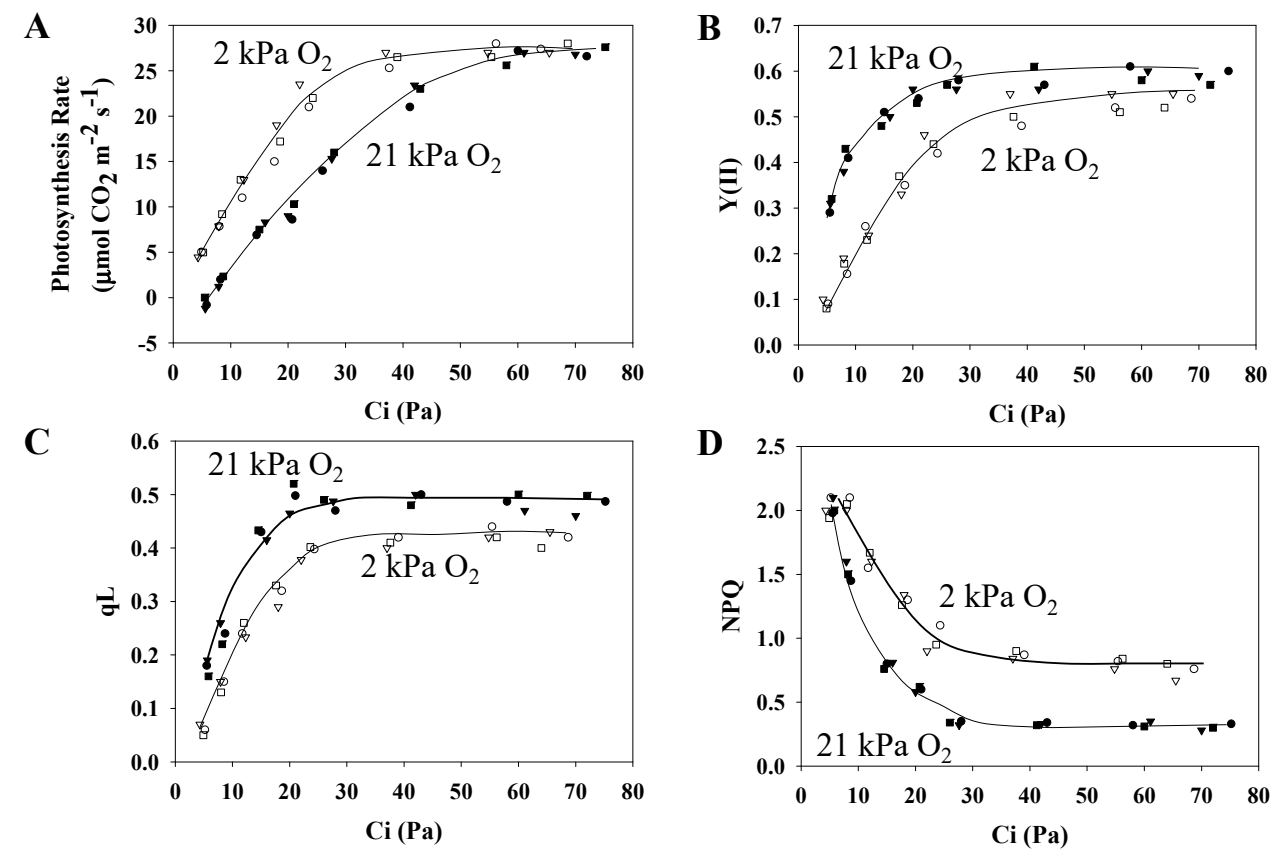

Figure 1. Influence of the partial pressure of $\mathrm{O}_{2}$ on the photosynthesis rate and chlorophyll (Chl) fluorescence parameters as a function of the partial pressure of intercellular $\mathrm{CO}_{2}$ (Ci) in wheat leaves. Photosynthesis rates (A) were measured at 21 and $2 \mathrm{kPa} \mathrm{O}_{2}$, at $500 \mu \mathrm{mol}$ photons $\mathrm{m}^{-2} \mathrm{~s}^{-1}$, simultaneously with the measurement of the effective quantum yield of photosystem II (PSII) (Y(II)) (B), the photochemical quenching of Chl fluorescence, the $\mathrm{Q}_{\mathrm{A}}$ oxidized state (qL) (C), and the non-photochemical quenching (NPQ) of Chl fluorescence (D). Data were obtained from three independent experiments using leaves attached to three wheat plants ( $N=3$ : sample 1 , circle; 2 , square; 3 , triangle). The ambient partial pressures of $\mathrm{CO}_{2}$ were changed from 100 to 5 through $80,60,40,30,20$, and $10 \mathrm{~Pa}$ at 21 and $2 \mathrm{kPaO}_{2}$ for the same leaves. Closed symbols, $21 \mathrm{kPa} \mathrm{O}_{2}$; open symbols, $2 \mathrm{kPa} \mathrm{O}_{2}$. Lines in the graphs were arbitrarily drawn to indicate the trends of the data. 
A

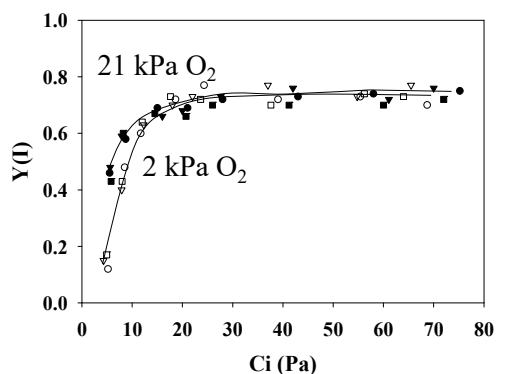

B

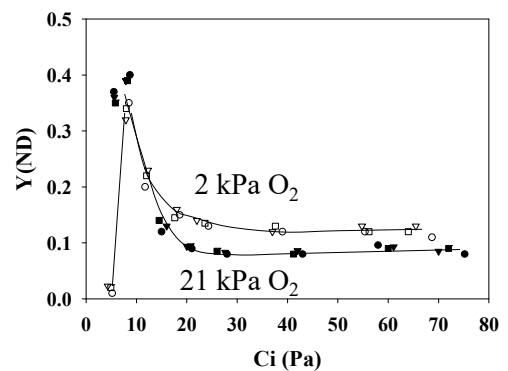

C

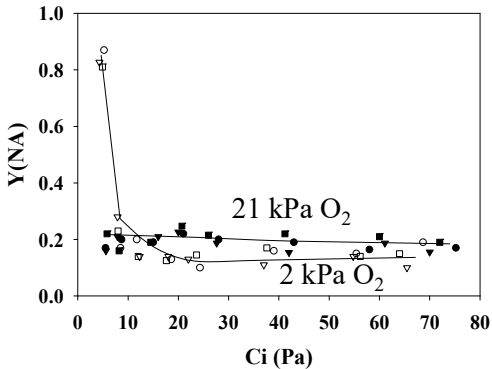

Figure 2. Influence of the partial pressure of $\mathrm{O}_{2}$ on the redox state of P700 in PSI as a function of the partial pressure of intercellular $\mathrm{CO}_{2}(\mathrm{Ci})$ in wheat leaves. The effective quantum yield of photosystem I (PSI) (Y(I)) (A), the oxidized state of P700 (Y(ND)) (B), and the excited state of P700 $(\mathrm{Y}(\mathrm{NA}))(\mathrm{C})$ were simultaneously measured with the photosynthesis rate and chlorophyll fluorescence yield measurements. $\mathrm{Y}(\mathrm{I})+(\mathrm{ND})+\mathrm{Y}(\mathrm{NA})=1$. Data were obtained from three independent experiments using leaves attached to three wheat plants ( $N=3$ : sample 1 , circle; 2 , square; 3 , triangle). The ambient partial pressures of $\mathrm{CO}_{2}$ were changed from 100 to 5 through 80, 60, 40,30, 20, and $10 \mathrm{~Pa}$ at 21 and 2 $\mathrm{kPa} \mathrm{O}_{2}$ for the same leaves. Closed symbols, $21 \mathrm{kPa} \mathrm{O}_{2}$; open symbols, $2 \mathrm{kPa} \mathrm{O}_{2}$. Lines in the graphs were arbitrarily drawn to indicate the trends of the data.

The following parameters were plotted against the leaf intercellular $\mathrm{CO}_{2}$ partial pressure (Ci) under the two $\mathrm{pO}_{2}$ conditions: the photosynthesis rate (Figure 1A), the PSII quantum yield (Y(II)) (Figure 1B), qL reflecting the $\mathrm{Q}_{\mathrm{A}}$ redox state in PSII (Figure 1C), and NPQ (Figure 1D).

The photosynthesis rate under the normoxic condition showed a $\mathrm{CO}_{2}$ compensation point of approximately $6 \mathrm{~Pa} \mathrm{pCO}_{2}$, and the photosynthesis rate increased as $\mathrm{Ci}$ increased, becoming saturated at roughly $60 \mathrm{~Pa} \mathrm{Ci}$ (Figure $1 \mathrm{~A}$ ). On the other hand, under the hypoxic condition, the $\mathrm{CO}_{2}$ compensation point decreased, and the photosynthesis rate was even greater than that under the normoxic condition. This is because, under the hypoxic condition, photorespiration was suppressed [31,36]. Y(II) also increased as $\mathrm{Ci}$ increased (Figure 1B). However, unlike the photosynthesis rate, $\mathrm{Y}(\mathrm{II})$ values were greater under the normoxic condition rather than under the hypoxic condition. This reflects the increased electron sink provided by photorespiration [31]. Furthermore, as with Y(II), qL showed a response to changes of both $\mathrm{Ci}$ and $\mathrm{pO}_{2}$ (Figure $1 \mathrm{C}$ ); that is, $\mathrm{Q}_{\mathrm{A}}$ was oxidized in response to $\mathrm{Y}(\mathrm{II})$ increasing, and this was caused by the increased electron sink provided by photorespiration [31]. NPQ decreased in response to the increase in Y(II) (Figure 1D). Furthermore, the increase in both Y(II) and qL facilitated by photorespiration lowered the NPQ values further under the normoxic condition than under the hypoxic condition, considering that (Equation (6)) [37]

$$
\mathrm{NPQ}=\mathrm{qL} \times[1-\mathrm{Y}(\mathrm{II})] / \mathrm{Y}(\mathrm{II}) \times(\mathrm{Fv} / \mathrm{Fm}) /[1-(\mathrm{Fv} / \mathrm{Fm})]
$$

The quantum yields of PSI were plotted against $\mathrm{Ci}$ under the two $\mathrm{pO}_{2}$ conditions: $\mathrm{Y}(\mathrm{I})$ (Figure 2A), $\mathrm{Y}(\mathrm{ND})$ (Figure 2B), and Y(NA) (Figure 2C).

$\mathrm{Y}(\mathrm{I})$ increased as $\mathrm{Ci}$ increased (Figure 2A). Unlike the photosynthesis rate, the $\mathrm{Y}(\mathrm{I})$ values were approximately the same under the normoxic condition. On the other hand, under the hypoxic condition, $\mathrm{Y}(\mathrm{I})$ decreased to roughly 0.15 when $\mathrm{Ci}$ was lower than $5 \mathrm{~Pa}$, where photosynthesis and photorespiration activities were negligible. Furthermore, Y(ND), representing the oxidation level of P700, also showed a response to Ci changes (Figure 2B). Drops in Ci led to increases in Y(ND). $\mathrm{Y}(\mathrm{ND})$ under the normoxic condition was lower than under the hypoxic condition, above $15 \mathrm{~Pa} \mathrm{Ci}$. Meanwhile, under photorespiration-suppressed conditions, the suppression of photosynthesis activity in the $\mathrm{Ci}$ range lower than $10 \mathrm{~Pa}$ caused $\mathrm{Y}(\mathrm{ND})$ to fall to roughly 0.01 . However, $\mathrm{Y}(\mathrm{ND})$ did not fall in the same $\mathrm{Ci}$ range under the normoxic condition. Y(NA) did not depend on photorespiration activity and showed no $\mathrm{Ci}$ response (Figure 2C), except when photorespiration was suppressed and $\mathrm{Ci}$ was low, where Y(NA) only increased to approximately 0.85 . Below $10 \mathrm{~Pa} \mathrm{Ci}$ under the hypoxic condition, 
photosynthesis and photorespiration, that is, almost all electron sinks, were suppressed, as shown by the extremely small Y(I) and Y(II). Because of the suppressed electron flux in both PSII and PSI, the P700 oxidation reflected in Y(ND) was suppressed and Y(NA) was enhanced.

\subsection{Characteristics of the Electrochromic Shift Signal and $\mathrm{H}^{+}$Conductance in Response to Changes in $\mathrm{pCO}_{2}$}

To reveal the effects of photorespiration on the electrochromic shift $\left(\mathrm{ECS}_{\mathrm{N}}\right)$ signal and on $\mathrm{H}^{+}$ conductance $\left(\mathrm{gH}^{+}\right)$, we analyzed the effects of $\mathrm{pCO}_{2}$ on photosynthesis in wheat leaves. The methods for analyzing the photosynthesis rate and these parameters are described in Figure 1 (Figure 3A).

A

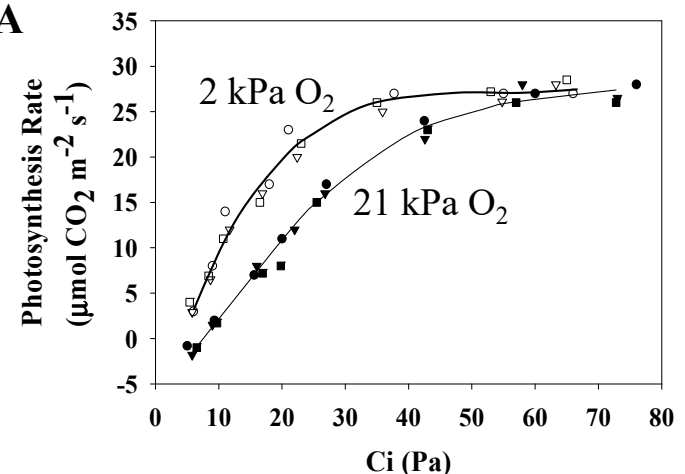

C

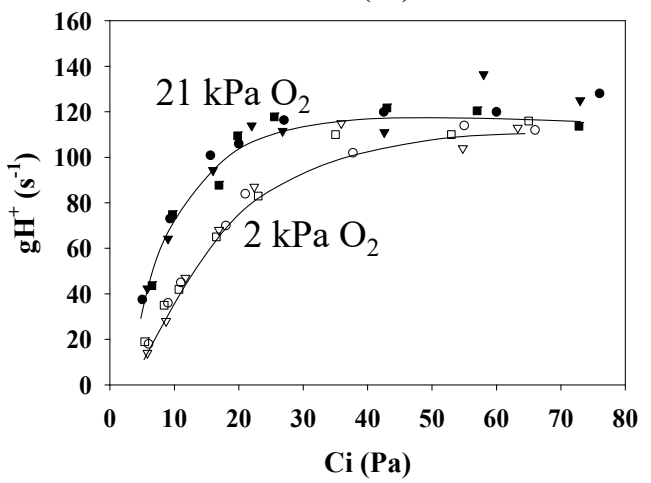

B

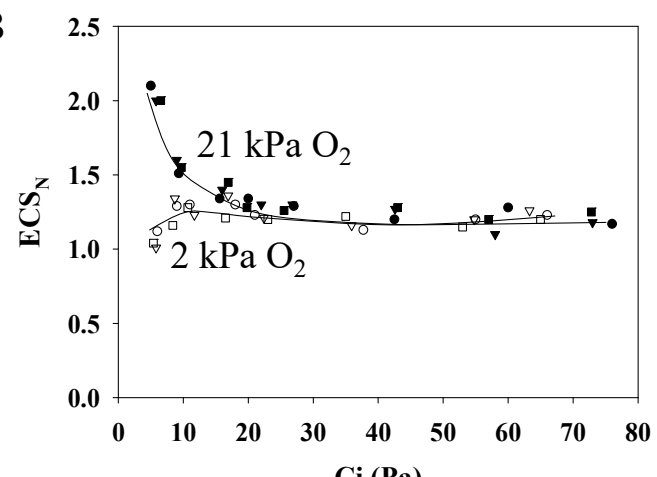

D

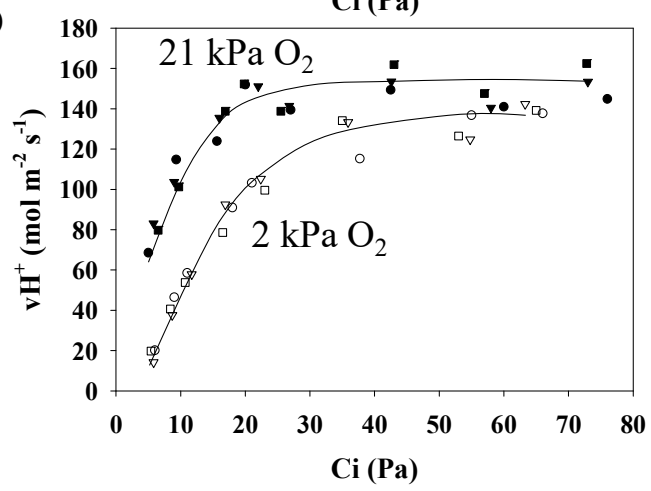

Figure 3. Influence of the partial pressure of $\mathrm{O}_{2}$ on the parameters of proton motive force reflected as an electrochromic shift (ECS) signal, $\mathrm{H}^{+}$conductance $\left(\mathrm{gH}^{+}\right)$, and the ECS decay rate $\left(\mathrm{vH}^{+}\right)$due to $\mathrm{CO}_{2}$ fixation and photorespiration as a function of the partial pressure of intercellular $\mathrm{CO}_{2}(\mathrm{Ci})$ in wheat leaves. Photosynthesis rates (A) were measured at 21 and $2 \mathrm{kPa} \mathrm{O}_{2}$, at $500 \mu \mathrm{mol}$ photons $\mathrm{m}^{-2} \mathrm{~s}^{-1}$, simultaneously with the measurements of electrochromic shift $\left(\mathrm{ECS}_{\mathrm{N}}\right)(\mathbf{B}), \mathrm{H}^{+}$conductance $\left(\mathrm{gH}^{+}\right)(\mathbf{C})$, and the ECS decay rate $\left(\mathrm{vH}^{+}\right)(\mathbf{D})$. Data were from three independent experiments using leaves attached to three wheat plants ( $N=3$ : sample 1 , circle; 2 , square; 3 , triangle). The ambient partial pressures of $\mathrm{CO}_{2}$ were changed from 100 to 5 through 80, 60, 40, 30, 20, and $10 \mathrm{~Pa}$ at 21 and $2 \mathrm{kPa} \mathrm{O}_{2}$ for the same leaves. Closed symbols, $21 \mathrm{kPa} \mathrm{O}_{2}$; open symbols, $2 \mathrm{kPa} \mathrm{O}_{2}$. Lines in the graphs were arbitrarily drawn to indicate the trends of the data.

The following parameters were plotted against $\mathrm{Ci}$, under normoxic and hypoxic conditions: the photosynthesis rate (Figure $3 \mathrm{~A}$ ), $\mathrm{ECS}_{\mathrm{N}}$ (Figure $3 \mathrm{~B}$ ), $\mathrm{gH}^{+}$(Figure $3 \mathrm{C}$ ), and the $\mathrm{ECS}_{\mathrm{N}}$ decay rate $\left(\mathrm{vH}^{+}\right)$ (Figure 3D).

ECS $_{N}$ did not show Ci dependence in response to the photorespiration-suppressed situation of the hypoxic condition (Figure 3B). In contrast, in the photorespiration-functional situation of the normoxic condition, lowering Ci caused $\mathrm{ECS}_{\mathrm{N}}$ to increase, suggesting that photorespiration contributed to $\Delta \mathrm{pH}$ induction. Under both normoxic and hypoxic conditions, the proportion of $\Delta \mathrm{pH}$ in the $\mathrm{ECS}_{\mathrm{N}}$ was over $90 \%$, while the proportion of $\Delta \Psi$ was under $10 \%$ (Figure S1A,B). As with $\mathrm{Y}(\mathrm{II}), \mathrm{gH}^{+}$showed $\mathrm{Ci}$ dependence (Figure $3 \mathrm{C}$ ). The $\mathrm{gH}^{+}$values were greater under the normoxic condition than under the hypoxic condition. Furthermore, as with both $\mathrm{Y}(\mathrm{II})$ and $\mathrm{gH}^{+}, \mathrm{vH}^{+}$showed $\mathrm{Ci}$ dependence (Figure 3D). 
The value of $\mathrm{vH}^{+}$was estimated by multiplying $\mathrm{gH}^{+}$by $\mathrm{ECS}_{\mathrm{N}}$ (see Section 2, "Materials and Methods"). These facts support that photorespiration increased $\mathrm{vH}^{+}$in the thylakoid membrane, compared to the hypoxic condition.

\subsection{Electron Flux of Photosynthetic LEF Matches the Rate of ECS Deay Driven by Photosynthesis and Photorespiration}

We examined the relationship between the electron flux in photosynthetic linear electron flow (LEF) and the $\mathrm{H}^{+}$consumption flux of both photosynthesis and photorespiration in the thylakoid membrane. In this study, Jf, reflecting $\mathrm{LEF}$, and $\mathrm{vH}^{+}$, were not measured simultaneously. Therefore, the Jf values were plotted against $\mathrm{A}+\mathrm{Rd}$, based on Figure 1 (Figure S2A). The relationships between Jf and $\mathrm{A}+\mathrm{Rd}$ are shown by the arbitrarily drawn lines, which represent the trend of the data. Furthermore, the $\mathrm{vH}^{+}$ values were plotted against $\mathrm{A}+\mathrm{Rd}$ based on Figure 3 (Figure S2B). The relationships between $\mathrm{vH}^{+}$and $\mathrm{A}+\mathrm{Rd}$ are shown as the same as with Jf. In Figure S2A,B, Jf and $\mathrm{vH}^{+}$were sampled at the same values of $\mathrm{A}+\mathrm{Rd}$, on the basis of the arbitrarily drawn lines. Then, $\mathrm{vH}^{+}$was plotted against the Jf values (Figure 4A). Under the two $\mathrm{pO}_{2}$ conditions, $\mathrm{vH}^{+}$showed a positive linear relationship with Jf, with an origin of zero. These results agree with those of Avenson et al. [26] Kadota et al. [38] reported that the electron flux in ferredoxin (Fd)-dependent cyclic electron flow (CEF) activity is negligible compared to the electron flux in LEF under high light intensity conditions [38]. Therefore, it is implied that in a steady state, $\mathrm{vH}^{+}$is equal to the rate of $\mathrm{H}^{+}$accumulation in the thylakoid lumen driven by LEF.

A

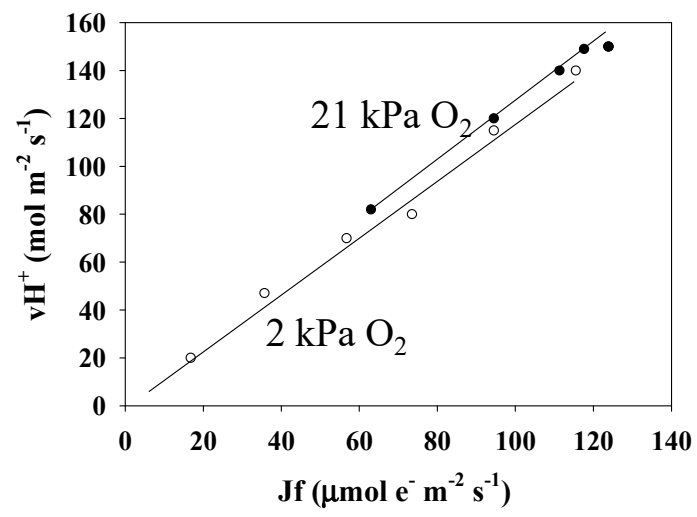

\section{B}

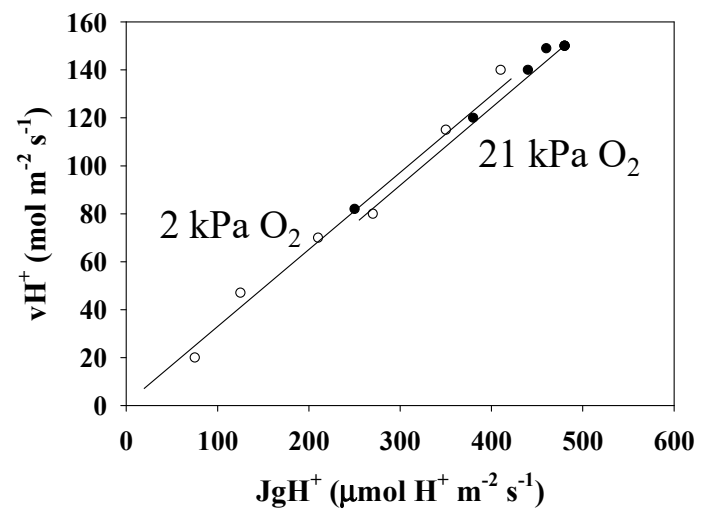

Figure 4. Relationships between the ECS decay rate $\left(\mathrm{vH}^{+}\right)$and the electron flux in photosynthetic linear electron flow (Jf), reflected as $\alpha \times \mathrm{Y}(\mathrm{II}) \times \mathrm{PFD}$, and between $\mathrm{vH}^{+}$and the $\mathrm{H}^{+}$consumption rate $\left(\mathrm{JgH}^{+}\right)$. The data for $\mathrm{vH}^{+}$, Jf, and $\mathrm{JgH}^{+}$were obtained from Figure $\mathrm{S} 2$ (see further details in the text). (A) $\mathrm{vH}^{+}$was plotted against Jf. (B) $\mathrm{vH}^{+}$was plotted against $\mathrm{JgH}^{+}$. Closed symbols, $21 \mathrm{kPa}_{2}$; open symbols, $2 \mathrm{kPa} \mathrm{O}_{2}$. Lines in the graphs were arbitrarily drawn to indicate the trends of the data.

Next, we estimated the flux of $\mathrm{H}^{+}$consumption $\left(\mathrm{JgH}^{+}\right)$for the regeneration of ATP that is required for driving photosynthesis and photorespiration, on the basis of the Ci dependence data for both the photosynthesis rate and Y(II) (Figure 1A,B) (see "Materials and Methods" [32]). $\mathrm{JgH}^{+}$values were plotted against $\mathrm{A}+\mathrm{Rd}$ (Figure $\mathrm{S} 2 \mathrm{C}$ ). In Figure $\mathrm{S} 2 \mathrm{~B}, \mathrm{C}, \mathrm{vH}^{+}$and $\mathrm{JgH}^{+}$were sampled at the same A + $\mathrm{Rd}$ values (Figure $2 \mathrm{~A}, \mathrm{~B}$ ). Then, $\mathrm{vH}^{+}$was plotted against $\mathrm{JgH}^{+}$(Figure $4 \mathrm{~B}$ ). Under both normoxic and hypoxic conditions, $\mathrm{vH}^{+}$showed a positive linear relationship with $\mathrm{JgH}^{+}$, with an origin of zero. These results agree with the results of Sejima et al. [32]. These sets of results show that the $\mathrm{vH}^{+}$is determined by the ATP regeneration rate in photosynthesis and photorespiration. From the fact that LEF driven by photosynthesis and photorespiration shows a clear linear relationship with $\mathrm{vH}^{+}$having an origin point of zero, we can conclude that the light reaction tightly couples with the dark reaction; that is, these results also support that the activities of alternative electron flows producing $\Delta \mathrm{pH}$ across thylakoid membranes, the water-water cycle, and/or Fd-CEF, are extremely low and/or negligible. 


\subsection{Contribution of Photorespiration to P700 Oxidation and ECS $S_{N}$ in Response to Changes in the $H^{+}$ Consumption Rate}

The role of photorespiration in P700 oxidation was assessed (Figure 5). Under the normoxic condition, decreases in $\mathrm{JgH}^{+}$from 450 to $250 \mu \mathrm{mol} \mathrm{H} \mathrm{H}^{+} \mathrm{m}^{-2} \mathrm{~s}^{-1}$ induced by lowering Ci enhanced P700 oxidation, as shown by the increase in $\mathrm{Y}(\mathrm{ND})$, compared to the hypoxic condition (Figure 5A). These results indicate that photorespiration contributes to the oxidation of P700 in PSI. We tried to clarify the molecular mechanism required to oxidize P700 by photorespiration, for which the reduction of $\mathrm{P} 700^{+}$should be suppressed in the P700 photo-oxidation reduction cycle. The $\mathrm{PQH}_{2} \mathrm{oxidation}$ activity exhibited by the Cyt $b_{6} / f$ complex is suppressed by the acidification of the luminal space of thylakoid membranes and RISE, which contribute to the suppression of the reduction of P700 ${ }^{+}$in PSI. A decrease in $\mathrm{JgH}^{+}$induces a reduction of PQ-pool, as shown by the decrease in $\mathrm{qL}$ under the normoxic condition, the extent of which was larger than that under the hypoxic condition (Figure 5D). These results correspond to those of Shaku et al. [8] and Shimakawa, Shaku et al. [10]. One of the molecular mechanisms for the oxidation of P700 is RISE [10]. Compared to the hypoxic condition, qL decreased much more under the normoxic condition (Figure 5D). The range of the smaller $\mathrm{qL}$ under the normoxic condition compared to the hypoxic condition corresponds to the range of the larger Y(ND). On the other hand, the acidification of the luminal space of thylakoid membranes suppresses $\mathrm{PQH}_{2}$ oxidation activity of the Cyt $b_{6} / f$ complex [24]. The $\Delta \mathrm{pH}$ was evaluated as the $\mathrm{ECS}_{\mathrm{N}}$ increased in response to the decrease in $\mathrm{JgH}^{+}$under the normoxic condition, but did not change under the hypoxic condition (Figure 5B). That is, photorespiration stimulated the formation of $\Delta \mathrm{pH}$ across thylakoid membranes to suppress the $\mathrm{PQH}_{2}$ oxidation activity of the Cyt $b_{6} / f$ complex [24] and enhance the oxidation of P700. The reason why the $\Delta \mathrm{pH}$ increased under the normoxic condition could be because the values of $\mathrm{gH}^{+}$ were lower than those under the hypoxic condition (Figure $5 \mathrm{C}$ ). These facts suggest that the regulatory mechanism lowers the $\mathrm{H}^{+}$conductance of thylakoid membranes by photorespiration.
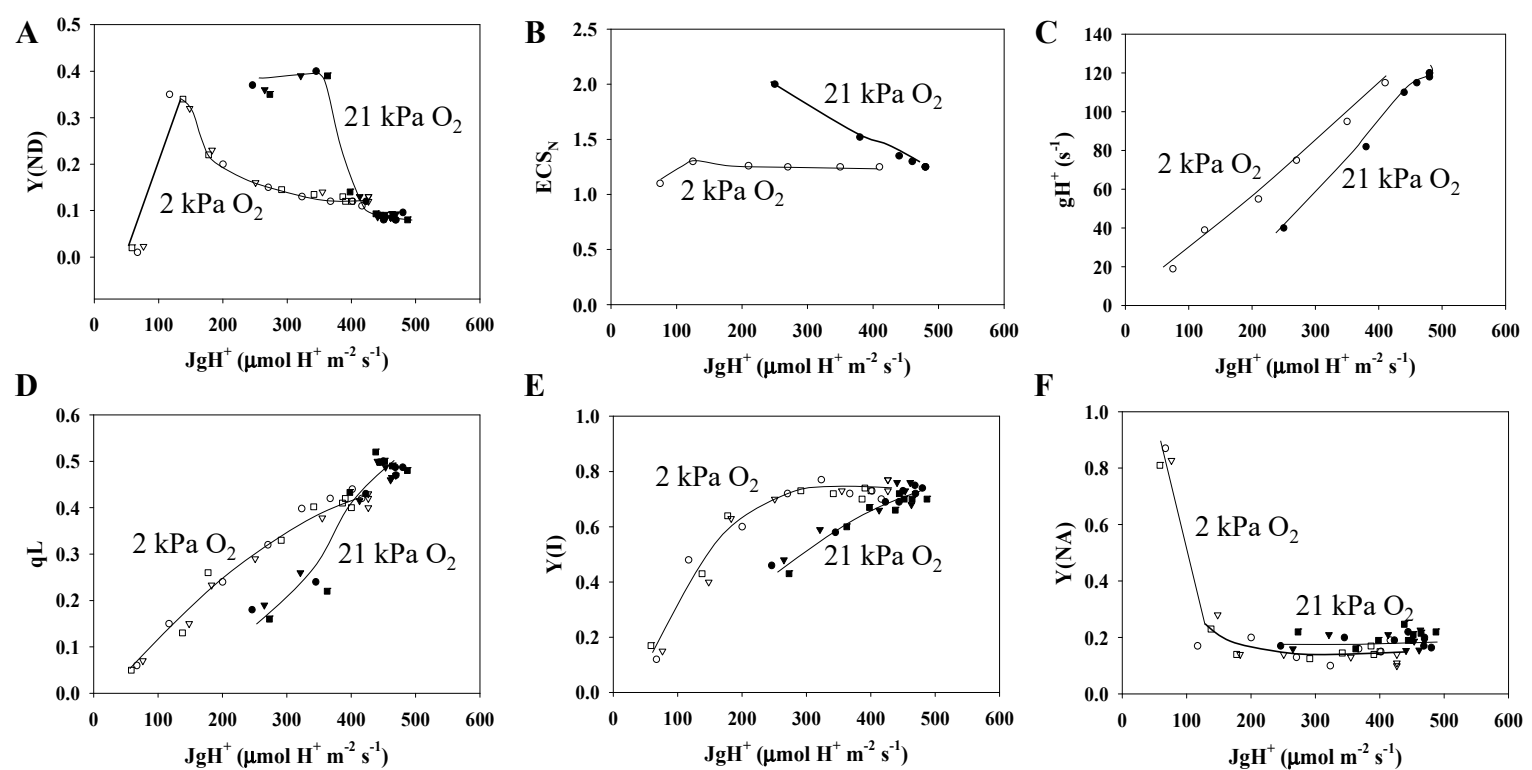

Figure 5. Relationships between $\mathrm{Y}(\mathrm{ND})$ and $\mathrm{JgH}^{+}, \mathrm{ECS}$ and $\mathrm{JgH}^{+}, \mathrm{gH}^{+}$and $\mathrm{JgH}^{+}, \mathrm{qL}$ and $\mathrm{JgH}^{+}, \mathrm{Y}(\mathrm{I})$ and $\mathrm{JgH}^{+}$, and $\mathrm{Y}(\mathrm{NA})$ and $\mathrm{JgH}^{+}$. The data for each parameter were taken from Figures $1-3$, and Figure S3 (see further details in the text). (A) Y(ND), (B) $\mathrm{ECS}_{\mathrm{N}},(\mathbf{C}) \mathrm{gH}^{+},(\mathbf{D}) \mathrm{qL},(\mathrm{E}) \mathrm{Y}(\mathrm{I})$, and (F) Y(NA) were plotted against $\mathrm{JgH}^{+}$at 21 and $2 \mathrm{kPaO}_{2}$. Closed symbols, $21 \mathrm{kPa} \mathrm{O}_{2}$; open symbols, $2 \mathrm{kPa} \mathrm{O}_{2}$. Lines in the graphs were arbitrarily drawn to indicate the trends of the data.

Under the normoxic condition, decreases in $\mathrm{JgH}^{+}$from 450 to $250 \mu \mathrm{mol} \mathrm{H} \mathrm{H}^{+} \mathrm{m}^{-2} \mathrm{~s}^{-1}$ lowered the electron flux in PSI, as shown in the decrease in $\mathrm{Y}(\mathrm{I})$, compared to the hypoxic condition (Figure $5 \mathrm{E}$ ). These results indicate that photorespiration suppresses the electron flux in PSI by enhancing the oxidation 
of P700, because Y(NA) did not change (Figure 5F); that is, the suppression of the photosynthetic linear electron flow from the Cyt $b_{6} / f$ complex to PSI gets preference over the activity of PSI under the normoxic condition. The oxidation of $\mathrm{P} 700$ lowers the chance of $\mathrm{O}_{2}$ being reduced to $\mathrm{O}_{2}{ }^{-}$at the acceptor side of PSI by decreasing Y(I) and keeping Y(NA) at a lower value. Under the hypoxic condition, $\mathrm{Y}(\mathrm{I})$ further decreased with the increase in Y(NA) below $250 \mu \mathrm{mol} \mathrm{H}^{+} \mathrm{m}^{-2} \mathrm{~s}^{-1}$ (Figure 5E,B). The increase in Y(NA), reflecting the accumulation of electrons at the acceptor side of PSI, is not dangerous for PSI, because the probability of producing ROS is too small under the hypoxic condition [3].

The results detailed above show that photorespiration contributes to P700 oxidation. The Ci dependencies of Rubisco's vc and vo were plotted under the normoxic and hypoxic conditions (Figure 6A,B). Furthermore, vo/vc was plotted against Ci (Figure 6C). These results show that vo increases owing to the decrease in $\mathrm{Ci}$, and that photorespiration activity increases under the normoxic condition. Interestingly, when $\mathrm{Ci}<20 \mathrm{~Pa}, \mathrm{Ci}$ decreases do not increase the photorespiration activity. These results agree with the results of Miyake and Yokota [31]. The causes of the suppression of the increase in photorespiration activity with the Ci drop will be discussed in the Discussion section. In contrast, the photorespiration activity was negligible under the hypoxic condition (Figure 6B).

A

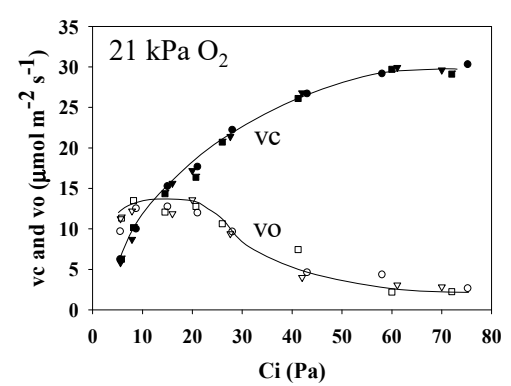

B

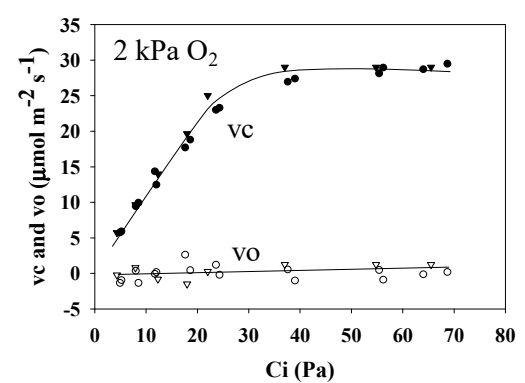

C

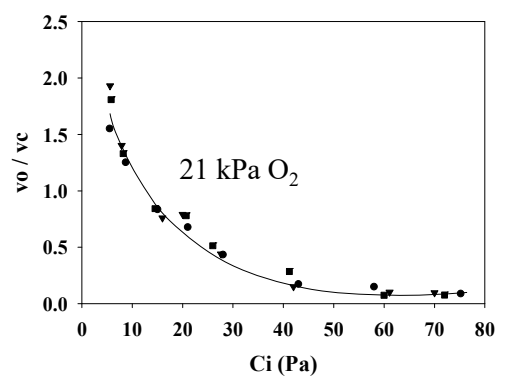

Figure 6. Influence of the intercellular partial pressure of $\mathrm{CO}_{2}(\mathrm{Ci})$ on both the ribulose 1,5-bisphosphate (RuBP) carboxylase reaction rate (vc) and the RuBP oxygenase reaction rate (vo) in wheat leaves. Photosynthesis rates were measured at 21 and $2 \mathrm{kPa} \mathrm{O}_{2}$, at $500 \mu \mathrm{mol}$ photons $\mathrm{m}^{-2} \mathrm{~s}^{-1}$, simultaneously with the measurement of chlorophyll fluorescence. Both vc and vo were estimated from the photosynthesis rates and the values of Y(II) [21]. Data were obtained from Figure 1 (sample 1, circle; 2, square; 3, triangle). (A) Both vc and vo were plotted against $\mathrm{Ci}$ at $21 \mathrm{kPa} \mathrm{O}$. Closed symbols, vc; open symbols, vo. (B) Both vc and vo were plotted against $\mathrm{Ci}$ at $2 \mathrm{kPa} \mathrm{O}$. Closed symbols, vc; open symbols, vo. (C) The values of vo/vc at $21 \mathrm{kPa} \mathrm{O}$ were plotted against $\mathrm{Ci}$. Lines in the graphs were arbitrarily drawn to indicate the trends of the data.

\section{Discussion}

In the present research, we tried to elucidate the physiological function of photorespiration in P700 oxidation in PSI. Generally, P700 is oxidized by the limitation of electron flow to the oxidized form of $\mathrm{P} 700, \mathrm{P} 700^{+}[1]$, and the oxidation activity of $\mathrm{PQH}_{2}$ of the cytochrome $b_{6} / f$ complex is down-regulated by the acidification of the luminal space (photosynthetic control) and RISE. We compared the relationship between P700 oxidation and photorespiration in terms of both photosynthetic control and RISE. We clarified that photorespiration decreased the $\mathrm{H}^{+}$conductance and $\mathrm{gH}^{+}$, induced $\Delta \mathrm{pH}$ formation, and simultaneously enhanced the reduction of PQ. These facts show that the rate of ATP consumption in photorespiration would be lower than that in photosynthesis; that is, a metabolic transition from only photosynthesis to both photosynthesis and photorespiration would cause a decrease in the efficiency of the regeneration of ATP due to photorespiration. The enhanced $\Delta \mathrm{pH}$ formation induced the reduction of $\mathrm{PQ}$ to further suppress the $\mathrm{PQH}_{2}$ oxidation activity of the $\mathrm{Cyt} b_{6} / f$ complex. Photorespiration might induce RISE by $\Delta \mathrm{pH}$ formation.

We next considered the molecular mechanism for $\Delta \mathrm{pH}$ formation across the thylakoid membranes to understand the P700 oxidation mechanism. In C3 angiosperms, the electron flux in photosynthetic 
LEF showed a positive linear relationship (with an origin of zero) with electron consumption rates (Jg) in both photosynthesis and photorespiration [30,39]. These results show that photosynthetic LEF drives both photosynthesis and photorespiration activity. Furthermore, we recently found that the LEF rate and Fd oxidation rate have a similar relationship to that between the LEF rate and Jg [38]. These results show that ferredoxin (Fd)-dependent CEF [40-46] is negligibly small; that is, photosynthetic $\mathrm{LEF}$ is responsible for the majority of $\Delta \mathrm{pH}$ formation [38]. The induction mechanism of $\Delta \mathrm{pH}$ formation across the thylakoid membranes is shown in the following manner: $\Delta \mathrm{pH}$ formation is observed as an ECS signal increase $[26,47]$. Then, the ECS generation and decay rate $[\mathrm{d}(\mathrm{ECS}) / \mathrm{dt}]$ are determined by the difference between the ECS generation rate dependent on the LEF flux (Jf $=\alpha \times Y(I I) \times$ PFD, see the detail in "Materials and Methods") and the ECS decay rate $\left(\mathrm{vH}^{+}\right)$of the ATP regeneration reaction required for photosynthesis and photorespiration (Equations (7) and (8)),:

$$
\begin{gathered}
\mathrm{d}\left(\mathrm{m} \times \mathrm{ECS}_{\mathrm{N}}\right) / \mathrm{dt}=\mathrm{k} \times \mathrm{Jf}-\mathrm{vH}^{+}, \\
=\mathrm{k} \times \mathrm{Jf}-\mathrm{m} \times \mathrm{gH}^{+} \times \mathrm{ECS}_{\mathrm{N}} .
\end{gathered}
$$

The coefficient $\mathrm{k}$ reflects $\mathrm{H}^{+}$accumulation in the lumens, which is driven by LEF, and depends on $\mathrm{H}_{2} \mathrm{O}$ oxidation in PSII and on Q-cycle rotation in the Cyt $b_{6} / f$ complex. Furthermore, $\mathrm{vH}^{+}$is expressed as $\mathrm{m} \times \mathrm{gH}^{+} \times\left(\mathrm{ECS}_{\mathrm{N}}\right)$. The $\mathrm{gH}^{+}, \mathrm{H}^{+}$conductance is a rate constant that reflects the apparent rate constant of ECS decay. The $\mathrm{vH}^{+}$reflects the $\Delta \mathrm{pH}$ dissipation rate, and $\mathrm{vH}^{+}$can be replaced with $\mathrm{JgH}^{+}$ as follows (Equation (9)):

$$
\mathrm{d}\left(\mathrm{m} \times \mathrm{ECS}_{\mathrm{N}}\right) / \mathrm{dt}=\mathrm{k} \times \mathrm{Jf}-\mathrm{JgH}^{+} .
$$

The validity of $\mathrm{vH}^{+}=\mathrm{JgH}^{+}$is provided by the fact that the relationship between the two in a steady state is shown to be positive and linear, with an origin of zero (Figure 4B). This confirms that $\mathrm{vH}^{+}$is equal to the $\mathrm{H}^{+}$usage rate for the ATP regeneration required for photosynthesis and photorespiration. These results agree with the results of [32].

We could confirm that, in a steady state where $\left[\mathrm{d}\left(\mathrm{m} \times \mathrm{ECS}_{\mathrm{N}}\right) / \mathrm{dt}=0\right], \mathrm{vH}^{+}$shows a positive linear relationship with the LEF rate, with an origin of zero (Figure $4 \mathrm{~A}$ ). These results agree with the results of [26]. Therefore, the fact that $\mathrm{vH}^{+}$reflects $\mathrm{JgH}^{+}$shows that the ATP consumed in photosynthesis and photorespiration can only be supplied by LEF; that is to say, the following relationship is proposed (Equation (10)):

$$
\mathrm{k} \times \mathrm{Jf}=\mathrm{m} \times \mathrm{gH}^{+} \times \mathrm{ECS}_{\mathrm{N}}=\mathrm{JgH}^{+} .
$$

Equation (4) shows that LEF activity links photosynthesis and photorespiration activity through $\Delta \mathrm{pH}$ formation and dissipation. From these results (Equations (11) and (12)),

$$
\begin{gathered}
\mathrm{ECS}_{\mathrm{N}}=(\mathrm{k} \times \mathrm{Jf}) /\left(\mathrm{m} \times \mathrm{gH}^{+}\right), \\
=\mathrm{JgH}^{+} /\left(\mathrm{m} \times \mathrm{gH}^{+}\right) .
\end{gathered}
$$

Based on this model, we will discuss the molecular mechanism of P700 oxidation.

The primary causes of P700 oxidation under the hypoxic condition, in which only photosynthesis functions, can be explained as follows. Decreases in $\mathrm{JgH}^{+}$gradually oxidized P700 (Figure 5A). However, the $\mathrm{ECS}_{\mathrm{N}}$ values remained the same (Figure 5B). Meanwhile, decreases in $\mathrm{JgH}^{+}$lowered $\mathrm{gH}^{+}$(Figure 5C). The ratio of the $\mathrm{JgH}^{+}$decrease was equal to the ratio of the $\mathrm{gH}^{+}$decrease. This is the reason that $\mathrm{ECS}_{\mathrm{N}}$ remained constant (equations (5) and (6)). We found that $\mathrm{qL}$ decreased along with decreases in $\mathrm{JgH}^{+}$(Figure 5D). This shows that the PQ pool is reduced along with the lowering of Jf [48]. This may be the reason why RISE is induced [1,8,10,49]. RISE caused by PQ reduction induces $\mathrm{P} 700$ oxidation by lowering the activity of $\mathrm{PQH}_{2}$ oxidation of the Cyt $b_{6} / f$ complex.

Next, we attempted to elucidate how photorespiration contributes to the oxidation of P700 in PSI. In the photorespiratory situation under the normoxic condition, the decrease in $\mathrm{JgH}^{+}$from 400 to $200 \mu \mathrm{mol} \mathrm{H} \mathrm{H}^{+} \mathrm{m}^{-2} \mathrm{~s}^{-1}$ enhanced the increase in $\mathrm{Y}(\mathrm{ND})$ compared to the non-photorespiratory situation 
under the hypoxic condition (Figure $5 \mathrm{~A}$ ). $\mathrm{ECS}_{\mathrm{N}}$ also increased, which was due to the enhanced decrease in $\mathrm{gH}^{+}$, compared to the decrease in $\mathrm{JgH}^{+}$(Figure 5C; Equation (6)). Furthermore, qL also decreased under the normoxic condition compared to the hypoxic condition (Figure 5D); that is, photorespiration oxidized P700 by photosynthetic control through $\Delta \mathrm{pH}$ formation and RISE through PQ reduction.

In this study, we discovered important facts about photorespiration. Under the normoxic condition, the values of $\mathrm{gH}^{+}$were lower compared to under the hypoxic condition, in the range of $\mathrm{JgH}^{+}$from 250 to $400 \mu \mathrm{mol} \mathrm{H} \mathrm{H}^{+} \mathrm{m}^{-2} \mathrm{~s}^{-1}$ (Figure $5 \mathrm{C}$ ). This fact shows that the activity of ATP synthase might decrease under the normoxic condition. The detailed mechanism for this remains to be clarified.

When photorespiration functions, both $\mathrm{gH}^{+}$and $\mathrm{qL}$ decrease, both of which induce photosynthetic control and RISE (Figure 5C,D). This contributes to the oxidation of P700 in PSI, as described above. On the other hand, we found suppressed rates of the ribulose-1,5-bisphosphate (RuBP) carboxylase reaction (vc) and RuBP oxygenase reaction (vo), catalyzed by RuBP carboxylase/oxygenase (Rubisco) (Figure 6). Following Rubisco kinetics, a decrease in Ci should cause an increase in vo [34-36]. The data in Figure 6 correspond to the results of Miyake and Yokota [31]. RISE has the potential to lower LEF activity while simultaneously contributing to P700 oxidation [8]. These facts show that the photosynthetic electron transport reaction, a light reaction, regulates both photosynthesis and photorespiration with the oxidation of P700 in PSI.

Supplementary Materials: The following are available online at http://www.mdpi.com/2223-7747/9/3/319/s1, Figure S1: Both $\Delta \mathrm{pH}$ and $\Delta \Psi$ which contribute to proton motive force (pmf), reflected as the total electrochromic shift (ECS) signal, were separately determined with ECS in Figure 3 following the method of Cruz et al. (2001), Figure S2: Relationships of $\mathrm{Y}(\mathrm{II}), \mathrm{vH}^{+}, \mathrm{JgH}^{+}, \mathrm{ECS}$, and $\mathrm{gH}^{+}$with $(\mathrm{A}+\mathrm{Rd})$, Figure S3: Dependence of $\mathrm{Jf}_{\text {and }} \mathrm{JgH}^{+}$ on $\mathrm{Ci}$, and the relationship between $\mathrm{JgH}^{+}$and $\mathrm{Jf}$.

Author Contributions: S.W. and C.M. performed the experiments and data analysis; S.W., Y.S., and C.M. wrote the article; C.M. conceived the research plan and supervised the experiments. All authors have read and agreed to the published version of the manuscript.

Funding: This work was supported by JST CREST Grant Number JPMJCR1503, Japan.

Acknowledgments: The authors are thankful to MDPI for English language editing.

Conflicts of Interest: The author declares no conflict of interest.

\section{References}

1. Shimakawa, G.; Miyake, C. Oxidation of P700 ensures robust photosynthesis. Front. Plant Sci. 2018, 9, 1617. [CrossRef]

2. Asada, K. THE WATER-WATER CYCLE IN CHLOROPLASTS: Scavenging of Active Oxygens and Dissipation of Excess Photons. Annu. Rev. Plant Physiol. Plant Mol. Biol. 1999, 50, 601-639. [CrossRef] [PubMed]

3. Sejima, T.; Takagi, D.; Fukayama, H.; Makino, A.; Miyake, C. Repetitive short-pulse light mainly inactivates photosystem I in sunflower leaves. Plant Cell Physiol. 2014, 55, 1184-1193. [CrossRef] [PubMed]

4. Shimakawa, G.; Shaku, K.; Miyake, C. Oxidation of P700 in Photosystem I Is Essential for the Growth of Cyanobacteria. Plant Physiol. 2016, 172, 1443-1450. [CrossRef] [PubMed]

5. Zivcak, M.; Brestic, M.; Kunderlikova, K.; Sytar, O.; Allakhverdiev, S.I. Repetitive light pulse-induced photoinhibition of photosystem I severely affects $\mathrm{CO}_{2}$ assimilation and photoprotection in wheat leaves. Photosynth Res. 2015, 126, 449-463. [CrossRef]

6. Charepanov, D.A.; Milanovsky, G.E.; Petrova, A.A.; Tikhonov, A.N.; Semenov, A.Y. Electron transfer through the acceptor side of photosystem I: Interaction with exogenous acceptors and molecular oxygen. Biochemistry (Moscow) 2017, 82, 1249-1268. [CrossRef]

7. Shimakawa, G.; Murakami, A.; Niwa, K.; Matsuda, Y.; Wada, A.; Miyake, C. Comparative analysis of strategies to prepare electron sinks in aquatic photoautotrophs. Photosynth Res. 2019, 139, 401-411. [CrossRef]

8. Shaku, K.; Shimakawa, G.; Hashiguchi, M.; Miyake, C. Reduction-Induced Suppression of Electron Flow (RISE) in the Photosynthetic Electron Transport System of Synechococcus elongatus PCC 7942. Plant Cell Physiol. 2016, 57, 1443-1453. [CrossRef] 
9. Shimakawa, G.; Matsuda, Y.; Nakajima, K.; Tamoi, M.; Shigeoka, S.; Miyake, C. Diverse strategies of $\mathrm{O}_{2}$ usage for preventing photo-oxidative damage under $\mathrm{CO}_{2}$ limitation during algal photosynthesis. Sci. Rep. 2017, 7, 41022. [CrossRef]

10. Shimakawa, G.; Shaku, K.; Miyake, C. Reduction-Induced Suppression of Electron Flow (RISE) Is Relieved by Non-ATP-Consuming Electron Flow in Synechococcus elongatus PCC 7942. Front. Microbiol. 2018, 9, 886. [CrossRef]

11. Takagi, D.; Amako, K.; Hashiguchi, M.; Fukaki, H.; Ishizaki, K.; Goh, T.; Fukao, Y.; Sano, R.; Kurata, T.; Demura, T.; et al. Chloroplastic ATP synthase builds up a proton motive force preventing production of reactive oxygen species in photosystem I. Plant J. 2017, 91, 306-324. [CrossRef] [PubMed]

12. Takagi, D.; Ishizaki, K.; Hanawa, H.; Mabuchi, T.; Shimakawa, G.; Yamamoto, H.; Miyake, C. Diversity of strategies for escaping reactive oxygen species production within photosystem I among land plants: P700 oxidation system is prerequisite for alleviating photoinhibition in photosystem I. Physiol. Plant 2017, 161, 56-74. [CrossRef] [PubMed]

13. Golding, A.J.; Johnson, G.N. Down-regulation of linear and activation of cyclic electron transport during drought. Planta 2003, 218, 107-114. [CrossRef]

14. Miyake, C.; Miyata, M.; Shinzaki, Y.; Tomizawa, $\mathrm{K} . \mathrm{CO}_{2}$ response of cyclic electron flow around PSI (CEF-PSI) in tobacco leaves-relative electron fluxes through PSI and PSII determine the magnitude of non-photochemical quenching (NPQ) of Chl fluorescence. Plant Cell Physiol. 2005, 46, 629-637. [CrossRef] [PubMed]

15. Harbinson, J.; Foyer, C.H. Relationships between the Efficiencies of Photosystems I and II and Stromal Redox State in $\mathrm{CO}_{2}$-Free Air: Evidence for Cyclic Electron Flow in Vivo. Plant Physiol. 1991, 97, 41-49. [CrossRef]

16. Harbinson, J.; Genty, B.; Baker, N.R. Relationship between the Quantum Efficiencies of Photosystems I and II in Pea Leaves. Plant Physiol. 1989, 90, 1029-1034. [CrossRef]

17. Harbinson, J.; Genty, B.; Baker, N.R. The relationship between $\mathrm{CO}_{2}$ assimilation and electron transport in leaves. Photosynth Res. 1990, 25, 213-224. [CrossRef]

18. Harbinson, J.; Genty, B.; Foyer, C.H. Relationship between Photosynthetic Electron Transport and Stromal Enzyme Activity in Pea Leaves: Toward an Understanding of the Nature of Photosynthetic Control. Plant Physiol. 1990, 94, 545-553. [CrossRef]

19. Harbinson, J.; Hedley, C.L. Changes in P-700 Oxidation during the Early Stages of the Induction of Photosynthesis. Plant Physiol. 1993, 103, 649-660. [CrossRef]

20. Wada, S.; Takagi, D.; Miyake, C.; Makino, A.; Suzuki, Y. Responses of the Photosynthetic Electron Transport Reactions Stimulate the Oxidation of the Reaction Center Chlorophyll of Photosystem I, P700, under Drought and High Temperatures in Rice. Int. J. Mol. Sci. 2019, 20, 2068. [CrossRef]

21. von Caemmerer, S. Biochemical Models of Leaf Photosynthesis; CSIRO Publishing: Collingwood, Australia, 2000.

22. Baker, N.R.; Harbinson, J.; Kramer, D.M. Determining the limitations and regulation of photosynthetic energy transduction in leaves. Plant Cell Environ. 2007, 30, 1107-1125. [CrossRef] [PubMed]

23. Klughammer, C.; Schreiber, U. An improved method, using saturating light pulses, for the determination of photosystem I quantum yield via P700+-absorbance changes at $830 \mathrm{~nm}$. Planta 1994, 192, 261-268. [CrossRef]

24. Tikhonov, A.N. The cytochrome $b_{6} f$ complex at the crossroad of photosynthetic electron transport pathways. Plant Physiol. Biochem. 2014, 81, 163-183. [CrossRef] [PubMed]

25. Cruz, J.A.; Sacksteder, C.A.; Kanazawa, A.; Kramer, D.M. Contribution of electric field $(\Delta \psi)$ to steady-state transthylakoid proton motive force (pmf) in vitro and in vivo. control of pmf parsing into $\Delta \psi$ and $\Delta \mathrm{pH}$ by ionic strength. Biochemistry 2001, 40, 1226-1237. [CrossRef] [PubMed]

26. Avenson, T.J.; Cruz, J.A.; Kramer, D.M. Modulation of energy-dependent quenching of excitons in antennae of higher plants. Proc. Natl. Acad. Sci. USA 2004, 101, 5530-5535. [CrossRef]

27. Klughammer, C.; Siebke, K.; Schreiber, U. Continuous ECS-indicated recording of the proton-motive charge flux in leaves. Photosynth Res. 2013, 117, 471-487. [CrossRef]

28. Cornic, G.; Ghashghaie, J. Effect of temperature on net $\mathrm{CO}_{2}$ assimilation and photosystem II quantum yield of electron transfer of French bean (Phaseolus vulgaris L.) leaves during drought stress. Planta 1991, 185, 255-260. [CrossRef]

29. Cornic, G.; Briantais, J.M. Partitioning of photosynthetic electron flow between $\mathrm{CO}_{2}$ and $\mathrm{O}_{2}$ reduction in a C3 leaf (Phaseolus vulgaris L.) at different $\mathrm{CO}_{2}$ concentrations and during drought stress. Planta 1991, 183, 178-184. [CrossRef] 
30. Genty, B.; Briantais, J.; Baker, N.R. The relationship between the quantum yield of photosynthetic electron transport and quenching of chlorophyll fluorescence. Biochim. Biophys. Acta 1989, 990, 87-92. [CrossRef]

31. Miyake, C.; Yokota, A. Determination of the rate of photoreduction of $\mathrm{O}_{2}$ in the water-water cycle in watermelon leaves and enhancement of the rate by limitation of photosynthesis. Plant Cell Physiol. 2000, 41, 335-343. [CrossRef]

32. Sejima, T.; Hanawa, H.; Shimakawa, G.; Takagi, D.; Suzuki, Y.; Fukayama, H.; Makino, A.; Miyake, C. Post-illumination transient $\mathrm{O}_{2}$-uptake is driven by photorespiration in tobacco leaves. Physiol. Plant 2016, 156, 227-238. [CrossRef] [PubMed]

33. Seelert, H.; Poetsch, A.; Dencher, N.A.; Engel, A.; Stahlberg, H.; Muller, D.J. Structural biology. Proton-powered turbine of a plant motor. Nature 2000, 405, 418-419. [CrossRef] [PubMed]

34. Farquhar, G.D. Models describing the kinetics of ribulose biphosphate carboxylase-oxygenase. Arch. Biochem. Biophys. 1979, 193, 456-468. [CrossRef]

35. Farquhar, G.D.; von Caemmerer, S.; Berry, J.A. A biochemical model of photosynthetic $\mathrm{CO}_{2}$ assimilation in leaves of C3 species. Planta 1980, 149, 78-90. [CrossRef] [PubMed]

36. Farquhar, G.D.; von Caemmerer, S.; Berry, J.A. Models of photosynthesis. Plant Physiol. 2001, 125, 42-45. [CrossRef]

37. Miyake, C.; Amako, K.; Shiraishi, N.; Sugimoto, T. Acclimation of tobacco leaves to high light intensity drives the plastoquinone oxidation system-relationship among the fraction of open PSII centers, non-photochemical quenching of Chl fluorescence and the maximum quantum yield of PSII in the dark. Plant Cell Physiol. 2009, 50, 730-743. [CrossRef]

38. Kadota, K.; Furutani, R.; Makino, A.; Suzuki, Y.; Wada, S.; Miyake, C. Oxidation of P700 Induces Alternative Electron Flow in Photosystem I in Wheat Leaves. Plants 2019, 8, 152. [CrossRef]

39. Ruuska, S.A.; Badger, M.R.; Andrews, T.J.; von Caemmerer, S. Photosynthetic electron sinks in transgenic tobacco with reduced amounts of Rubisco: Little evidence for significant Mehler reaction. J. Exp. Bot. 2000, 51, 357-368. [CrossRef]

40. Munekage, Y.; Hojo, M.; Meurer, J.; Endo, T.; Tasaka, M.; Shikanai, T. PGR5 is involved in cyclic electron flow around photosystem I and is essential for photoprotection in Arabidopsis. Cell 2002, 110, 361-371. [CrossRef]

41. Shikanai, T. Regulatory network of proton motive force: Contribution of cyclic electron transport around photosystem I. Photosynth Res. 2016, 129, 253-260. [CrossRef]

42. Shikanai, T.; Yamamoto, H. Contribution of Cyclic and Pseudo-Cyclic Electron Transport to the Formation of Proton Motive Force in Chloroplasts. Mol. Plant 2017, 10, 20-29. [CrossRef] [PubMed]

43. Yamamoto, H.; Shikanai, T. PGR5-Dependent Cyclic Electron Flow Protects Photosystem I under Fluctuating Light at Donor and Acceptor Sides. Plant Physiol. 2019, 179, 588-600. [CrossRef] [PubMed]

44. Yamamoto, H.; Takahashi, S.; Badger, M.R.; Shikanai, T. Artificial remodelling of alternative electron flow by flavodiiron proteins in Arabidopsis. Nat. Plants 2016, 2, 16012. [CrossRef] [PubMed]

45. Yamori, W.; Shikanai, T. Physiological Functions of Cyclic Electron Transport Around Photosystem I in Sustaining Photosynthesis and Plant Growth. Annu. Rev. Plant Biol. 2016, 67, 81-106. [CrossRef]

46. Yamori, W.; Makino, A.; Shikanai, T. A physiological role of cyclic electron transport around photosystem I in sustaining photosynthesis under fluctuating light in rice. Sci. Rep. 2016, 6, 20147. [CrossRef]

47. Kramer, D.M.; Avenson, T.J.; Edwards, G.E. Dynamic flexibility in the light reactions of photosynthesis governed by both electron and proton transfer reactions. Trends Plant Sci. 2004, 9, 349-357. [CrossRef]

48. Shimakawa, G.; Miyake, C. Changing frequency of fluctuating light reveals the molecular mechanism for P700 oxidation in plant leaves. Plant Direct 2018, 2, e00073. [CrossRef]

49. Zhang, M.M.; Fan, D.Y.; Murakami, K.; Badger, M.R.; Sun, G.Y.; Chow, W.S. Partially dissecting electron fluxes in both photosystems in spinach leaf discs during photosynthetic induction. Plant Cell Physiol. 2019. [CrossRef]

(C) 2020 by the authors. Licensee MDPI, Basel, Switzerland. This article is an open access article distributed under the terms and conditions of the Creative Commons Attribution (CC BY) license (http://creativecommons.org/licenses/by/4.0/). 